\title{
Relações teóricas entre a escolha na Economia Comportamental e a decisão de investimento em Keynes
}

\author{
The theoretical association between behavioral economics \\ and investment decisions in Keynes
}

\author{
Lucas Casonato ${ }^{\dagger}$ \\ Auberth Henrik Venson ${ }^{\ddagger}$ \\ Adriana Sbicca
}

\begin{abstract}
Resumo
O artigo explora a relação entre a decisão de investimento em Keynes e a pesquisa em Economia Comportamental. Para a identificação de elementos teóricos comuns entre essas duas abordagens, suas contribuições são brevemente recuperadas na história do pensamento econômico. A discussão desenvolvida contrasta elementos que sustentam as duas correntes, promovendo uma leitura de seus aspectos teóricos complementares: (i) racionalidade e incerteza; (ii) heurísticas e convenções; (iii) decisão individual e decisão de investimento. Isso permite uma compreensão mais profunda dessas propostas, e um entendimento melhor acerca: (1) do papel da subjetividade na Economia Comportamental a partir da utilização do conceito de heurísticas na análise da decisão de investimento em Keynes; e (2) dos aspectos psicológicos apontados por Keynes que explicam como elementos que influenciam a decisão de investimento (taxa de juros, por exemplo), não são determinantes nas escolhas. $\bigcirc$ trabalho sustenta uma complementariedade da Teoria dos Prospectos e a Contabilidade Mental com a análise psicológica de fatores apontados por Keynes como fundamentais na decisão de investimento: animal spirit, expectativa de retorno e taxa de juros, incerteza fundamental e a relação entre eficiência marginal do capital e taxa de juros.
\end{abstract}

Palavras-chave: Economia Comportamental; Keynes; Decisão de investimento.

Classificação JEL: D91; B22; E12.

\begin{abstract}
The article explores the relationship between the investment decision in Keynes and research in Behavioral Economics. For the identification of common theoretical elements between these two approaches, their contributions were briefly recovered from the history of economic thought. The developed discussion contrasts elements that support the two currents of thought, promoting a reading of their complementary theoretical aspects: (i) rationality and uncertainty; (ii) heuristics and conventions; (iii) individual decision and investment decision. This allows a deeper understanding of these proposals, and a better understanding about: (1) the role of subjectivity in Behavioral Economics from using the concept of heuristics in the analysis of the Keynes' investment decision; and (2) the psychological aspects pointed out by Keynes that explain how elements that influence the investment decision (interest rate, for example), are not determinants in choices. The work supports a complementarity of Prospect Theory and Mental Accounting with the psychological analysis of aspects pointed out by Keynes as fundamental in the investment decision: animal spirit, expected return and interest rate, fundamental uncertainty and the relationship between marginal capital efficiency and interest rate.
\end{abstract}

Keywords: Behavioral Economics; Keynes; Investment decision.

JEL Classification: D91; B22; E12.

\footnotetext{
** Os autores agradecem os comentários valiosos do professor Guilherme Ricardo dos Santos Souza e Silva e de outros dois pareceristas anônimos que avaliaram o artigo. O presente trabalho foi realizado com apoio da Coordenação de Aperfeiçoamento de Pessoal de Nivel Superior Brasil (CAPES) - Código de Financiamento 001.

+ Professor de Economia da PUCPR. E-mail: casonato.economia@gmail.com.

* Professor do Departamento de Economia da UEL. E-mail: auberth.eco@gmail.com.

\$Professora do Departamento de Economia da UFPR. E-mail: adsbicca@ufpr.br.
} 


\section{Introdução}

A "Teoria Geral” (TG) de Keynes surgiu e se destacou no cenário econômico por discutir um problema que a teoria tradicional se via incapaz de lidar, o do desemprego (Vieira, 2007). Com a Economia Comportamental, considerada um campo de estudo da economia que incorpora desenvolvimentos da Psicologia, não foi diferente. Resultou da existência de uma gama de trabalhos relacionando esses dois campos no debate sobre a limitação ou irrealismo nas hipóteses da teoria econômica tradicional em meados do século XX (e.g. Katona, 1953; Simon, 1959). A partir de 1970 essa discussão se intensificou, tornando-se mais importante ao mostrar empiricamente os padrões inconsistentes das decisões individuais (e.g. Tversky e Kahneman, 1974; Kahneman e Tversky, 1979; Thaler, 1985, 1987, 1988). Desta forma, tanto a proposta de Keynes como a Economia Comportamental compartilham o mérito de perceber um problema na teoria dominante quanto a sua capacidade de explicar fenômenos observados. Ainda, cada época apresentou abordagens alternativas ao mainstream que lhes rendeu atenção no ambiente acadêmico (e.g. Kahneman, 2012; Oreiro, 2011).

A literatura abordando a relação teórica entre a Economia Comportamental e a contribuição de Keynes cresceu em períodos recentes, principalmente na admissão da incerteza como elemento comum na explicação da tomada de decisão ${ }^{5}$. Um tópico frequente nessas abordagens é a divergência dos comportamentos individuais observados com relação àqueles previstos na teoria econômica tradicional, sobretudo quando da hipótese das expectativas racionais (Howitt, 1997; Silva e Curado, 2016).

Segundo Davidson (1999, 2002, 2003), o conceito de incerteza empregado por Keynes, ao diferir do risco probabilístico, configura um tal estado de desconhecimento na economia que impede sua mensuração, mas não imobiliza a tomada de decisões. Como explica Dequech (1999b), na presença dessa incerteza o futuro deve ser entendido como não ergódico, ou seja, não previsivelmente confiável com base em métodos estatísticos. Apesar desse alto grau de subjetividade, essa constatação não implica uma ignorância absoluta e paralisante dos agentes, que, ao dar-se conta de tais condições, internalizam-nas em suas decisões.

A Economia Comportamental também considera que a incerteza é um agravante para a escolha racional dos indivíduos, implicando na necessidade de adotar parâmetros para a inferência dos possíveis resultados futuros de cada alternativa presente. Para Katona (1953), a incerteza pode ser responsável pela

\footnotetext{
${ }^{5}$ São exemplos os trabalhos de Fontana e Gerrard (2004), Fazzari (2009), Pech e Milan (2009), Davidson (2010) e Koutsobinas (2014).
} 
mudança das decisões porque, mesmo que o agente esteja defronte as mesmas opções, ela pode afetar a percepção do cenário em que a escolha é realizada. De acordo com Simon (1979), as pessoas enfrentam problemas de armazenamento e processamento das informações, devido à racionalidade limitada. E essa situação é agravada pela incerteza, implicando que os agentes também incorporem em suas decisões os possíveis resultados das alternativas com que se deparam.

Assim, ambas as abordagens consideram que os indivíduos reconhecem a incerteza em que atuam, o que influencia suas decisões. Cada uma delas destaca fatores que simplificam a tomada de decisão dos agentes. Por exemplo, Fazzari (2009) aponta para a centralidade da noção de incerteza em Keynes para o entendimento das escolhas individuais, enfatizando as convenções e normas utilizadas pelos agentes descritos na TG como guia do seu comportamento. A Economia Comportamental, do mesmo modo, reconhece a existência de fatores que servem de guia na simplificação do processo de escolha. Kahneman (2012) discute diversos deles, denominados heurísticas, auxiliando a decisão nos contextos em que os resultados não são plenamente conhecidos, como é o caso do futuro, situação em que inerentemente prevalece a condição de incerteza.

Considerando conjuntamente as duas propostas, de Keynes e da Economia Comportamental, Koutsobinas (2014) argumenta que a tomada de decisão sob incerteza não envolve conhecimento sobre o futuro, mas uma inferência psicológica acerca dele baseada no conhecimento presente. Logo, neste autor a teoria de Keynes é compatível com a proposta da heurística da Economia Comportamental na medida em que na TG os agentes usam atributos de simplificação para enfrentar o futuro. Ou seja, valem-se de atalhos mentais para decidir com relação a um ambiente incerto.

Para Fontana e Gerrard (2004), a análise da decisão sob incerteza de Keynes comporta a abordagem de heurísticas e vieses de Tversky e Kahneman, destacando a similaridade no desenvolvimento da teoria da decisão entre Keynes e a Economia Comportamental. Pech e Milan (2009) também encontram relações teóricas entre os temas abordados por Keynes na TG e pela Economia Comportamental. Esses autores dão destaque ao papel das convenções no comportamento dos indivíduos, ao animal spirit dos empresários, à formação de expectativas e à propensão a consumir. Davidson (2010) e Koutsobinas (2014) vão além, afirmando que alguns insights de Keynes são originais, precursores de temas que vieram a ser discutidos na Economia Comportamental.

Embora Keynes tenha apontado para a influência de fatores psicológicos nas escolhas de todos os agentes econômicos, como será visto no artigo, particularizou alguns elementos como fundamentais na decisão de investimento dos empresários. 
Na Economia Comportamental, entretanto, embora efeitos psicológicos possam se manifestar de maneira particular de acordo com a categoria em que o indivíduo é estudado, se como consumidor ou empresário, seus efeitos gerais afetam a todas as decisões humanas. Deste modo, para relacionar Keynes e Economia Comportamental, o presente artigo tem como objetivo relacionar a decisão de investimento em Keynes às modernas teorias da decisão na Economia Comportamental para gerar uma maior compreensão acerca de ambas. Para isso, recuperam-se na história do pensamento econômico as proposições originais dessas abordagens para identificar os elementos teóricos a respeito de decisão que sejam, simultaneamente: (1) base de sustentação de suas teorias particulares; e (2) comuns entre as duas abordagens para que possam ser contrastados.

O restante do trabalho se divide em mais quatro seções. Na segunda seção são resgatados os elementos centrais que compõem a explicação das escolhas na ótica da Economia Comportamental, enquanto a terceira seção trata das variáveis explicativas do investimento em Keynes. A quarta seção recupera as propostas de aproximação entre as duas abordagens e analisa a possibilidade de complementariedade entre elas com base na decisão de investimento em Keynes e as modernas teorias da decisão na Economia Comportamental, do Prospecto e da Contabilidade Mental. Na quinta seção são tecidas as considerações finais do artigo.

\section{Racionalidade e heurística das escolhas na Economia Comportamental}

A Economia Comportamental surgiu a partir das contribuições de Herbert Simon na teoria da tomada decisão. Simon (1959) explorou o tema a partir do questionamento da hipótese sobre a racionalidade utilizada na teoria econômica mainstream. ${ }^{6}$ Conquanto mais de meio século tenha decorrido da contribuição seminal de Simon, ajudando a dar forma à Economia Comportamental como campo de estudo, ainda não há uma definição precisa do que esse nome de fato representa. Segundo Diamond e Vartianem (2007), o termo "Economia Comportamental" serve como guarda-chuva para abordagens diversas que buscam estender a análise econômica padrão de modo a levar em conta características do comportamento humano que estão ausentes nos modelos de tomada de decisão na economia tradicional.

\footnotetext{
${ }^{6}$ O presente artigo segue a definição de Just (2013) para o emprego do termo "teoria econômica mainstream", buscando defini-la como a teoria da escolha racional que tem como base o modelo de tomada de decisão por meio da maximização de utilidade. Esta definição é conveniente na medida em que permite denominar de mainstream tanto a teoria neoclássica que tomava forma à época de Keynes quanto àquela a partir da qual surge e se desenvolve a Economia Comportamental.
} 
A principal característica que define a Economia Comportamental atualmente é a convicção de que aumentar o realismo dos fundamentos psicológicos na análise econômica melhora o campo da economia. Porém, essa convicção não significa necessariamente rejeitar a abordagem econômica mainstream por completo, que continua sendo útil ao fornecer uma abordagem aplicável a várias formas de comportamento econômico (Camerer e Loewenstein, 2004). Nesta linha, de acordo com Just (2013), o objetivo da Economia Comportamental se concentra em compreender comportamentos observados que se desviam desse modelo econômico padrão, vieses de escolha que são chamados de anomalias. ${ }^{7}$

Essas anomalias contradizem os resultados esperados dos modelos econômicos tradicionais, e a Economia Comportamental busca explicar a racionalidade envolvida nesse processo, principalmente com o uso de elementos da psicologia na explicação (Just, 2013). Assim a Economia Comportamental permite expandir o alcance da teoria econômica ao propor explicações para situações com as quais a abordagem tradicional é incapaz de lidar, as anomalias.

A Economia Comportamental compreende diversos elementos teóricos, mas dois são aqui resgatados, racionalidade e heurística, com a finalidade de contrastálos com seus correspondentes na teoria da decisão de investimento em Keynes.

\subsection{Racionalidade na Economia Comportamental}

As primeiras discussões acerca da racionalidade em autores considerados precursores no campo da Economia Comportamental, em meados do século XX, partiram de críticas às hipóteses da teoria econômica tradicional sobre o agente econômico. Para Katona (1953), o conceito de racionalidade utilizado na teoria tradicional da tomada de decisão está associado à consistência nas escolhas, implicando que sob as mesmas opções os agentes deveriam repetir a decisão, tornando rígido o processo decisório. Porém, segundo Katona (1953), toda escolha sob a condição de racionalidade deve ser um processo para a solução de problemas, o que não é compatível com a rigidez no condicionamento prévio das decisões. Então a racionalidade deve implicar que o comportamento racional é flexível e adaptável, permitindo ao indivíduo considerar aspirações e objetivos de acordo com as circunstâncias com que se depara. Dessa forma, Katona (1953) salientou que as escolhas dependem do ambiente, ou da percepção que se tem dele, no momento da decisão.

\footnotetext{
7 Para uma discussão mais detalhada sobre anomalias ver a séria de publicações feitas por Richard Thaler no Journal of Economic Perspectives denominada Anomalies em que são discutidas as principais anomalias (e.g. Thaler, 1987, 1988; Dawes e Thaler, 1988; Loewenstein e Thaler, 1989; Kahneman, Knetsch e Thaler, 1991).
} 
A racionalidade limitada foi outra contribuição importante da Economia Comportamental construída a partir da crítica ao mainstream da teoria econômica. Simon $(1959,1979)$ propôs esse conceito a partir da constatação da falta de aderência à realidade da racionalidade perfeita e de sua fragilidade em descrever os comportamentos observados. No primeiro momento Simon (1959) discutiu a ideia de maximização de utilidade, e depois Simon (1979) levou em consideração a capacidade humana de captar, guardar e utilizar informações.

Simon (1959) apontou o problema de se considerar a maximização da utilidade como o objetivo racional dos agentes na tomada de decisão. No lugar de buscar um máximo alcançável, os indivíduos podem racionalmente buscar um nível almejado de utilidade aquém do maior, conquanto seja satisfatório do ponto de vista individual. Desta forma, a racionalidade é mantida, embora uma decisão como essas contrarie o princípio de não-saciedade estabelecido na teoria tradicional.

Já sobre a discussão da capacidade humana no uso das informações, Simon (1979) recuperou a implicação das hipóteses sobre o agente econômico na teoria tradicional, de que o indivíduo pode perceber, armazenar e processar indefinidamente qualquer quantidade de conhecimento. Com isso, Simon (1979) mostrou o quão exigente era a hipótese de racionalidade perfeita sobre as capacidades humanas, propondo substituí-la pela racionalidade limitada, em que os agentes têm uma relação imperfeita com o conhecimento disponível. Nesta versão, o agente racional pode ter problemas diversos no uso das informações: para interpretá-las corretamente, para guardar a totalidade disponível, e para usá-las simultaneamente. Logo, cada decisão se torna diferente de outras, em que a limitação da racionalidade se intensifica em paralelo ao aumento no grau de complexidade da escolha.

Além da crítica à tese convencional da tomada de decisão, comum a essas proposições de Katona (1953) e Simon $(1959,1979)$, há também o papel agravante da incerteza sobre o processo decisório. A escolha é entendida como atividade complicada porque cada cenário envolve um desafio (Katona, 1953), e representa nova necessidade de absorver informações diversas e definir o resultado satisfatório para cada opção (Simon, 1959, 1979). Desta forma, a incerteza atua sobre as impressões que o indivíduo forma mentalmente acerca das implicações de cada opção disponível. Como o agente reconhece esse ambiente, sua percepção sobre o processo decisório se adapta, modificando a própria busca por informações no processo de escolha.

As visões de Katona $(1953)$ e Simon $(1959,1979)$ sobre a racionalidade procuraram aumentar o poder descritivo da abordagem teórica, buscando incorporar 
elementos dos processos cognitivos apontados pela psicologia, para que o conceito se aproximasse daquilo que os indivíduos fazem no mundo real. Katona (1953) salientou o ambiente e a capacidade humana de adaptação às circunstâncias, enquanto Simon $(1959,1979)$ enfatizou a busca por satisfação dos indivíduos e a limitação computacional que lhes é inerente.

Buscando avançar com relação à ideia de racionalidade limitada de Simon (1979), Gingerenzer (2001) propôs o conceito de racionalidade ecológica, que superou as dificuldades ocasionadas pela condição de incerteza apontadas por Katona $(1953)$ e Simon $(1959,1979)$. A ideia de racionalidade ecológica considera a estrutura do ambiente para a tomada de decisão, desde o cenário em que é realizada, as informações necessárias para a escolha, até as opções com que o indivíduo se depara (Gingerenzer, 2001), buscando entender quais fatores influenciam os processos de decisão que produzem bem-estar (Berg, 2014).

De acordo com Todd e Gingerenzer (2007), a racionalidade ecológica está relacionada com as interações mente-ambiente subjacentes à tomada de decisão, consistindo em um ajuste entre estruturas de mecanismos de processamento de informação na mente e estruturas de informações no mundo. Assim, três aspectos centrais são identificados: a mente (heurísticas de decisão), o mundo (padrões de informação) e como eles podem combinar. De acordo com Gingerenzer (2001), indivíduos ecologicamente racionais seriam aqueles capazes de adaptar suas estratégias na tomada de decisão de acordo com o ambiente incerto que reconhecem estar inseridos. Como fica estabelecido a partir de Gingerenzer (2019), o termo ambiente se refere às alternativas, pistas, critérios e outros fatores relevantes para o tomador de decisão.

A racionalidade ecológica trata do sucesso das estratégias cognitivas no mundo, medido através da precisão, frugalidade ou rapidez nas decisões. $\bigcirc$ comportamento ecologicamente racional surge do ajuste entre o ambiente no qual a decisão é tomada e o mecanismo de decisão particular que é aplicado a ele, que é a heurística selecionada pelo indivíduo para uma decisão específica (Todd e Gingerenzer, 2012).

Então, segundo Dekker e Remic (2019), o conceito de racionalidade ecológica de Gingerenzer tem como foco as heurísticas que atuam como intermediárias entre: indivíduos, o ambiente natural e a adequação entre indivíduos e ambiente. Portanto, o comportamento é ecologicamente racional se o conjunto de heurísticas empregadas nos processos decisórios forem funcionais no ambiente em que a decisões são tomadas. 


\subsection{Heurística na Economia Comportamental}

Um dos principais argumentos de Simon (1979) para rejeitar a maximização como resultado da escolha individual foi a influência exercida pelas heurísticas. Como elas funcionam como atalhos para as escolhas, facilitando o processo decisório, acabam levando à negligência de parâmetros requeridos para o cálculo de custos e benefícios que deveriam ser considerados para a decisão maximizadora.

Heurística é o termo empregado na Economia Comportamental para designar procedimento simples usados pelos indivíduos que ajuda a tomar decisões adequadas em substituição àqueles que requerem maior esforço e tempo, facilitando o processo decisório (Kahneman, 2012, cap. 9). Shah e Oppenheimer (2008) definiram a heurística como forma de redução no esforço durante a tomada de decisão. Já Gingerenzer e Gaissmaier (2011) apresentaram a definição de heurística como estratégia para tomada de decisão que ignora parte das informações, com o objetivo de decidir de maneira mais rápida, prudente e/ou precisa em relação aos métodos mais complexos de escolha.

Como mostrado por Tversky e Kahneman (1974), a adoção de heurísticas no processo de decisão pode levar a um comportamento enviesado, uma vez que simplificações de atributos são substitutos imperfeitos daqueles necessários para a escolha, podendo levar a erros sistemáticos.

Processos de simplificação de decisão fortemente influenciados por fatores psicológicos, também foram sustentados na teoria do Prospecto que tratava de decisões sob incerteza. Kahneman e Tversky (1979) aplicaram diversos experimentos que envolviam apostas simples e observaram como as pessoas escolhiam dentre as alternativas. Concluíram que o indivíduo não analisa necessariamente a posição final de seus recursos, como proposto pela teoria da Utilidade Esperada do mainstream econômico. Ele analisa perspectivas que são construídas sobre as alternativas de escolha e esse processo apresenta duas etapas. Na primeira, as perspectivas são analisadas, muitas vezes produzindo uma representação mais simplificada dos prospectos. Na segunda etapa, os prospectos são avaliados, e aquele com maior valor é escolhido. As características principais desta teoria são representadas numa curva em $\mathrm{S}$, que enfatiza as diferenças nas avaliações de ganhos e perdas, com especial ênfase para a aversão à perda.

Nesta abordagem, as decisões intuitivas são reforçadas e suas implicações analisadas. No início dos trabalhos de Kahneman e Tversky, havia um foco em algumas heurísticas específicas, mas a ideia de decisão heurística assumiu uma concepção mais ampla. A partir dos estudos sobre julgamento e os desenvolvimentos 
da psicologia cognitiva realizados após a publicação de 1974, Kahneman e Frederick (2002) revisitaram o conceito: uma decisão é mediada por heurística quando um atributo do objeto em julgamento, necessário para a decisão, é substituído por outro que mais facilmente vem à mente. "Quando a questão é difícil e uma solução apta não se acha disponível, a intuição ainda tem sua oportunidade: uma resposta pode vir facilmente à mente - mas não é uma resposta à questão original" (Kahneman, 2012, p. 21-22), isso é a essência das heurísticas intuitivas. Logo, uma avaliação pode ser considerada baseada em heurística quando se reconhece que esse processo não é realizado com as devidas variáveis, admitindo-se o uso de atributos representativos.

Gingerenzer e Brighton (2009) argumentaram que as heurísticas são empregadas não apenas por reduzirem o esforço no processo decisório, mas também por sua precisão - pelo fato de que elas funcionam. Gingerenzer e Gaissmaier (2011) destacaram que a precisão das heurísticas depende da estrutura do ambiente em que são utilizadas, o que, segundo Todd e Gingerenzer (2007), pode ou não permitir padrões de informação compatíveis com a heurística adotada. ${ }^{8}$

Para Gingerenzer e Todd (1999), quando o processo decisório é interpretado como forma de solucionar problemas, entende-se que cada heurística cumpre um papel diferente na decisão. Uma vez que as heurísticas fazem uso de atributos substitutos durante a escolha, diferindo quanto ao grau de substituição com que representam a característica necessária, permitem situações mais ou menos propícias ao seu uso. Para esses autores, os indivíduos usam conscientemente algumas heurísticas pelo próprio conhecimento que eles possuem sobre a situação, julgando se cabe ou não seu uso, bem como qual a heurística mais adequada.

Se o uso de heurísticas é uma atividade comum aos indivíduos nas decisões normais, como mostra Kahneman (2012), tal procedimento se torna prática comum no ambiente incerto. Em ambientes de incerteza é reconhecida a imprecisão das informações, bem como o caráter inerentemente especulativo dos resultados de cada uma das escolhas disponíveis aos indivíduos no processo decisório. De acordo com Gingerenzer (2008), em geral as heurísticas funcionam bem em ambientes de incerteza porque permitem explorar a capacidade do ambiente e evoluir a partir daí, constituindo um conjunto de ferramentas customizadas para solucionar diversos problemas.

Segundo Mousavi e Gingerenzer (2014), em situações incertas é que as estratégias baseadas em heurísticas obtêm sucesso na tomada de decisões, porque

\footnotetext{
8 Os padrões de informação da estrutura do ambiente podem ter como fonte processos físicos, biológicos, sociais e culturais (Todd e Gingerenzer, 2007).
} 
exploram a estrutura de informações do ambiente e contam com a simplicidade para superar a complexidade da situação. Para esses autores, as heurísticas são ferramentas desenvolvidas por aprendizado direto ou ao longo da evolução.

Neste cenário e sob o ponto de vista da Economia Comportamental, pode-se argumentar que é racional, no sentido de fazer o melhor uso possível das informações disponíveis, partir de estratégias heurísticas tomando como base parâmetros conhecidos, embora reconhecidamente substitutos, para a inferência psicológica acerca do futuro, cuja característica fundamental é a incerteza.

\section{Decisão de investimento em Keynes}

O livro "Teoria Geral do Emprego, do Juro e da Moeda" representa um marco na história do pensamento econômico. Nele, Keynes defendeu que a teoria econômica de sua época era incapaz de lidar com o problema do desemprego generalizado após a Grande Depressão. Como alternativa, os governos deveriam repensar sua participação na economia, a fim de recuperar o nível de gasto para ampliar a demanda efetiva.

Para tanto, Keynes precisou reconsiderar o funcionamento da economia para mostrar que o nível de demanda agregada que assegura o pleno emprego, em equilíbrio com a oferta agregada, não está previamente garantido. Principalmente porque os gastos privados dependem das decisões de todos os agentes econômicos, em especial dos empresários. Assim, para além das variáveis já consideradas na economia tradicional, são acrescidos os fatores psicológicos e as expectativas como condicionantes da demanda agregada, que invariavelmente tornam a demanda efetiva aquém daquela necessária ao pleno emprego (e.g. Keynes, 1936, capítulo 18).

À luz do que se conhece hoje sobre a Economia Comportamental, em especial os fatores descritos na segunda seção deste artigo, é possível revisitar a obra magna de Keynes e observar a riqueza de seu tratamento teórico a elementos psicológicos. Isso é feito nas duas próximas subseções, a primeira analisando o caso mais geral da psicologia como condicionante das decisões diversas na teoria de Keynes, e a segunda observando a formação psicológica de expectativas em um ambiente de incerteza. Esses elementos são revistos para que possam ser recuperados na quarta seção do trabalho para comparação com aqueles destacados na segunda seção do artigo.

\subsection{Psicologia e decisões em Keynes}

Em sua TG, Keynes (1936) abordou aspectos psicológicos que guiam o comportamento dos agentes em suas operações no mercado. $\bigcirc$ autor sustentou a dificuldade de um indivíduo analisar as alternativas de decisão e as consequências 
das ações e, consequentemente, identificar o comportamento que deve ser adotado. Aspectos psicológicos são fundamentais para a compreensão do comportamento individual frente às mudanças no contexto de decisão, que são abordados na obra de Keynes por meio dos fatores: "propensão marginal a consumir", destacando uma relação entre renda e consumo de natureza cultural em uma sociedade (Keynes, 1936, capítulo 9); "preferência pela liquidez", um fator de precaução usado pelos agentes, que fazem uma espécie de seguro ao reter moeda consigo para o enfrentamento de situações adversas (Keynes, 1936, capítulo 17); e a "eficiência marginal do capital", que será enfatizada no presente artigo, que é a expectativa empresarial sobre o retorno futuro dos investimentos na atividade produtiva da economia (Keynes, 1936, capítulo 11).

Todos esses elementos foram abordados por Keynes em termos de preferências individuais e específicas dos indivíduos, afetados por questões subjetivas que influenciam a economia. Logo, tais fatores impedem que sejam concebidas aos agentes econômicos respostas automáticas contingentes a determinadas mudanças que tornariam suas ações predeterminadas.

A influência da psicologia na teoria de Keynes é reforçada pelo tratamento de questões econômicas convencionais com base no comportamento dos indivíduos, e não necessariamente em relações paramétricas entre variáveis econômicas. Como fica ilustrado em uma passagem sobre a taxa de juros, um preço econômico admitido na teoria tradicional pela regulação entre demanda e oferta de fundos, mas que Keynes associa à eficiência marginal do capital, sustentando-a como resultado da psicologia humana:

[...] a taxa de juros e a eficiência marginal do capital referem-se particularmente ao caráter indefinido das expectativas reais; elas resumem o efeito, sobre as decisões de mercado dos homens, de todo tipo de dúvidas vagas e de flutuantes estados de confiança e coragem. Ou seja, elas pertencem a um estágio de nossa teoria no qual não estamos mais supondo um futuro definido e calculável (KEYNES, 1937a, p. 165, itálico original).

Reconhecida a influência de fatores psicológicos sobre o comportamento individual no arcabouço econômico desenhado por Keynes (1936, capítulos 3 e 18), soma-se a ele a incerteza inerente ao ambiente de negócios aí existente, um elementochave na obra Keynesiana. Esse complicador é, dentro desse sistema, reconhecido pelos agentes econômicos que o compõe, que sabem operar sem a garantia dos resultados especulados na tomada de decisão.

Desta forma, Keynes (1936, capítulos 12 e 15) apontou que esses indivíduos procuram realizar suas escolhas com relação ao futuro baseando-se em algum método. Na TG isso é denominado "convenção", o ato de utilizar o presente como representante das condições futuras na tomada de decisões sobre eventos que exijam 
conhecimento sobre o futuro. Porém, a convenção de especular sobre o futuro com base no presente é um comportamento generalizado, permitindo uma convenção maior que é realizada por todos na economia, embora cada um o faça de maneira particular.

Segundo Fazzari (2009), os indivíduos baseiam suas decisões em normas e convenções iniciadas nas interações e preferências individuais. Para Oreiro (2011), essas convenções funcionam como instituições que permitem a coordenação das atividades econômicas por reduzirem a incerteza - já que os agentes esperam certa regularidade nas decisões de seus pares. Portanto, escolhas baseadas em convenções são aquelas que utilizam informações do presente para criar expectativas como guia das decisões. Nesse sentido, Keynes (1936, capítulos 12 e 17) ainda destacou outro fator psicológico do indivíduo para o enfrentamento da incerteza: a confiança que ele tem na sua própria previsão, que depende em boa medida do próprio grau de incerteza que ele percebe.

Keynes (1937b) esclareceu que a tomada de decisão é feita considerando-se tanto as informações disponíveis como uma espécie de "conhecimento incerto" sobre o qual não se tem nenhuma garantia. Como sabem disso, os agentes são forçados a esquecer essa dificuldade e realizar suas escolhas como se esse conhecimento lhe fosse certo, o que é feito de três maneiras: (i) admitindo o presente como um guia mais acertado para o futuro do que as perspectivas que se tem com relação a ele; (ii) aceitando a opinião sobre o futuro que vigora na sociedade por meio dos preços e dos níveis de produção atuais, que servem de base na ausência de fatores perturbadores deste estado de coisas; (iii) considerando a crença de que a opinião agregada é melhor que a individual, permitindo ao agente seguir o fluxo do conjunto de opiniões agregadas. Todas elas, pode-se argumentar, atendem como tipos de convenção na proposta Keynesiana, algo que os indivíduos reconhecem fazer apesar das limitações percebidas, mas que possui o mérito de ser socialmente aceito porque é repetido pelos demais.

\subsection{Expectativas sob incerteza e a decisão de investimento em Keynes}

A expectativa é o elemento-chave da decisão de investimento em Keynes (1936, capítulos 5 e 11). Na TG, diferente da teoria econômica convencional, a decisão de investir não guarda necessariamente relação negativa com as variações na taxa de juros. Como apontado na obra, os investimentos podem aumentar mesmo quando a taxa de juros estiver subindo, desde que haja aumento na eficiência marginal do capital, uma variável que não pode ser mensurada porque é particularizada no julgamento individual. A centralidade da expectativa decorre da incerteza no ambiente em que as decisões são tomadas, implicando que não se sabe 
o efeito futuro de um investimento, já que não há garantia de compatibilidade entre o que os empresários esperam ao realizá-lo e seus resultados.

Revela-se, assim, a intenção Keynesiana de romper com o determinismo nas relações econômicas da teoria que lhe era contemporânea. Para Miranda (1997), a percepção de Keynes acerca da expectativa, bem como da racionalidade e do investimento, também influenciou o rompimento dele com o grupo que denominou de "clássicos". 9 descontentamento keynesiano foi, sobretudo, com a excessiva simplificação desses aspectos por meio das hipóteses utilizadas na teoria tradicional. Como se verifica em um artigo posterior à TG, Keynes (1937b) acusou a teoria "clássica" de afastar-se da realidade ao ignorar a dinâmica econômica, negligenciando o pouco conhecimento do mercado sobre suas condições futuras.

A análise da proposição Keynesiana para a decisão de investimento considera que Keynes atribuiu uma racionalidade aos agentes econômicos na TG cujo comportamento permite o aprendizado por tentativa-e-erro. Isso parte da constatação de Bresser-Pereira (2009), Corazza (2009) e Ferrari-Filho e Terra (2016), de que os indivíduos da TG aprendem de maneira indutiva. Ou seja, obtêm seu conhecimento por meio da experiência, tal que se deve reconhecer o caráter contextual das informações que utilizam na tomada de decisão, mas principalmente a sujeição à interpretação subjetiva a que estão confinadas no processo decisório por parte do indivíduo. Assim, serão destacados aqueles aspectos que, por esse método, condicionam a formação de expectativas empresariais por aprendizado em um ambiente de incerteza. São eles: o tempo, as informações, a confiança e a eficiência marginal do capital.

Keynes (1936, capítulos 3, 5 e 11) construiu seu arcabouço na TG para lidar com a incerteza. Nesse cenário, os agentes econômicos são afetados principalmente por serem incapazes de conhecer com precisão os eventos futuros, por mais próximos que estejam. É o que Davidson (1999, 2002, 2003) caracteriza como nãoergodicidade do processo econômico, situação em que só se pode conjecturar sobre as consequências das escolhas. Isso tem relevância ainda maior para a decisão de investimento, já que Keynes (1936, capítulos 5 e 11) aponta que seus retornos só ocorrem ao longo do tempo, enquanto seu custo pode ser dividido entre o momento presente e aqueles vindouros.

\footnotetext{
${ }^{9}$ Keynes denominou de escola/teoria clássica o pensamento econômico que lhe era contemporâneo porque este mantinha a tradição dos primeiros economistas (como Smith, Ricardo e Say) de postularem que o livre mercado alcançaria automaticamente o estado de equilíbrio com pleno uso dos recursos econômicos.
} 
Conquanto essa impossibilidade preditiva, há na TG uma divisão do tempo entre o curto e o longo prazo para os quais se formam diferentes expectativas, admitindo que eventos mais próximos sejam mais fáceis de predizer que aqueles mais distantes. No curto prazo há expectativa de retorno sobre os produtos passíveis de disponibilizar por meio da capacidade produtiva atual, enquanto para o longo prazo recaem as estimativas sobre rendimentos futuros a partir da ampliação do capital (Keynes, 1936, capítulos 5 e 12). Miranda (1997) simplificou a divisão temporal em Keynes: o curto prazo, englobando o período necessário à realização da produção; e o longo prazo, em que se concretizam os investimentos realizados.

Seguindo essa proposta, para Keynes nos dois períodos existiriam fatores que influenciam as expectativas do empresário na decisão de investimento, porque em ambos há sinalizadores da renda futura que a nova capacidade produtiva pode proporcionar. No presente, mais próximo ao curto prazo, está tudo aquilo que é conhecido com algum grau de certeza, incorporando o estado atual de coisas e as mudanças que se sabe estar ocorrendo. Isso configura o conjunto atual de informações sobre o presente. No futuro, mais próximo ao longo prazo, estão todos os eventos e fenômenos econômicos esperados, que os agentes imaginam com algum grau de confiança que venham a ocorrer. Estes componentes caracterizam o conjunto atual de informações que os indivíduos creem ter sobre o futuro.

Como procurou descrever o funcionamento da economia a partir da realidade na TG, Keynes admitiu rigidez para as expectativas daí advindas. Embora tenha considerado o estado corrente das expectativas como resultado de uma série daquelas que the antecederam, apontou que tal estado está sempre mudando, o que ocorre antes mesmo que cessem os efeitos do estado imediatamente anterior. ${ }^{10}$ Desta forma, a imaginação dos agentes afetaria a dinâmica intertemporal da economia por meio de seus resultados sobre o processo decisório, sejam eles diretos, a partir do que pensam os agentes, ou indiretos, a partir do resíduo que fica com a mudança do estado de expectativas. Mas, Keynes (1936, capítulo 12) advertiu, as expectativas passadas se tornam menos relevantes no processo decisório, porque já precificadas no momento da decisão, ao que as expectativas presentes sobre o futuro ganham papel fundamental de guiar os investimentos.

O problema aparece quando se admite conjecturar sobre uma condição inerentemente incerta como o futuro. Porque aí o empresário se depara com três

\footnotetext{
${ }^{10}$ Isso é verificado porque em Keynes (1936, capítulo 11) as expectativas passadas se encontram materializadas nos bens de capital a que deram origem. Assim, tais bens de capital, ao influenciar as decisões presentes, representam a interferência do conjunto de expectativas anterior sobre a sequência futura de eventos.
} 
conjuntos de informações: (i) as expectativas que se tinha no passado; (ii) as condições presentes da economia; e (iii) as expectativas sobre o futuro. Conquanto todas as três interfiram no processo decisório, a segunda tem lugar especial por carregar consigo um pouco das outras duas. Porque as condições presentes da economia refletem tanto as expectativas passadas, por meio dos bens de capitais disponíveis, quanto o que se espera para o futuro, pelos níveis de produção e preços praticados.

Segundo Keynes (1936, capítulo 12), tem pouco sentido conjecturar sobre algo que não se pode ter certeza, como o futuro, de modo que os fatores já conhecidos acabam recebendo peso mais que proporcional na decisão dos agentes. Porém, há na TG, como visto, o reconhecimento de que existe um fator ponderador adicional entre a influência das coisas conhecidas/dadas e as desconhecidas/esperadas, a confiança nas próprias crenças. Como Keynes (1937b) explicou posteriormente, não se pode ter muita ideia acerca dos resultados senão daqueles decorrentes das ações mais diretas, porque há uma série de fatores que modificam os desdobramentos ao longo do tempo. Se isso é válido para os indivíduos de maneira geral, é ainda mais relevante para os empresários, a quem Keynes (1936, capítulo 12) atribuiu a propensão a agir apesar da incerteza, o "animal spirit $^{\prime 1}$, que é ponderado pela confiança nas expectativas. ${ }^{12}$

Ainda assim, consideradas as informações conhecidas e esperadas, bem como a confiança dos agentes, Keynes deixou claro que a própria natureza humana tem um efeito potencial sobre a magnitude das decisões escolhidas. Uma vez que os indivíduos são dotados de sentimentos otimistas ou pessimistas, pelos mais diversos motivos, se verifica que isso também guiaria o nível de investimento, superestimando ou subestimando sua esperança matemática de retorno. Porém, o que se objetivou com essa consideração não foi uma discussão da natureza humana, mas, antes, foi chamar a atenção para o fato de que existem fenômenos econômicos que alteram o ânimo da sociedade como um todo, ou seja, que há efeitos subjetivos desses acontecimentos.

Esses elementos convergem para caracterizar uma das principais contribuições de Keynes (1936, capítulo 11), a ideia de eficiência marginal do capital, que em linguajar financeiro é a esperança média líquida dos retornos financeiros do capital. Na TG esse componente é o principal determinante dos investimentos, porque

\footnotetext{
${ }^{11}$ A versão em português da TG utilizada neste artigo traduziu o termo como "entusiasmo", mas preferiu-se aqui fazer menção ao termo original proposto por Keynes, "animal spirit".

12 Para Dequech (1999a) esta parte refere-se ao componente exógeno do animal spirit, ajudando a compor o "estado de expectativas" do empresário. Recomenda-se o artigo mencionado para uma discussão mais ampla sobre o conceito "animal spirit" e suas implicações na obra de Keynes.
} 
reflete o fluxo de rendas futuras que o empresário espera do aumento na capacidade produtiva; nas palavras de Miranda (1997, p. 103): "[...] antecipações dos agentes acerca do futuro que é, por definição, incerto".

Na eficiência marginal do capital já estão incluídos os custos esperados da realização do investimento, já que Keynes incluiu nele o preço de oferta do bem de capital, tornando-o "[...] a expectativa de lucro [...] a qual se vincula, no limite inferior, à vigente taxa de juros, e, no limite superior, à capacidade criadora da imaginação dos especuladores" (Szmerecsányi, 1984, p. 17). Em resumo, a decisão de investir ocorre na abordagem Keynesiana quando a renda esperada supera o gasto planejado em investimento, ou seja, quando a eficiência marginal do capital é positiva.

Keynes (1936, capítulo 11) foi categórico ao afirmar que a eficiência marginal do capital governa as decisões de investimento. Isso torna crucial o entendimento da relação entre incerteza e expectativas, por meio das variáveis acima destacadas (tempo, informações e confiança).

Logo, não se pode negar o caráter de completa subjetividade em que os investimentos são concebidos no arcabouço keynesiano, em que a mente empresarial tem papel central ao confirmar psicologicamente a concretização desses gastos por seus resultados. Como afirmou o próprio Keynes (1937c, p. 91, ênfase no original): "[...] o montante de investimento ex ante depende de decisões subjetivas de investir, que subjetivamente se tornarão objetivas". Uma decisão que, dependendo dos retornos esperados por meio da eficiência marginal do capital e da precaução que os indivíduos têm com relação ao futuro na Preferência pela Liquidez, torna-se dependente de "[...] dois conjuntos de opiniões sobre o futuro" (Keynes, 1937b, p. 175).

Com base nessa revisão proposta para a TG de Keynes, é possível atribuir-lhe a importância dos efeitos psicológicos na formação de expectativas por parte dos agentes econômicos. Uma vez que suas decisões são tomadas em ambiente incerto, voltadas para um futuro em que também prevalece a incerteza, as respostas individuais acabam sendo particulares, motivadas pelas expectativas que os indivíduos criam subjetivamente. Logo, isso torna o comportamento econômico algo psicologicamente condicionado, e não necessariamente contingente como reclamava Keynes à teoria tradicional de sua época. 


\section{A relação da Economia Comportamental com a decisão de investimento na Teoria Geral de Keynes}

Como mencionado na introdução deste artigo, não é nova a procura por relacionar a Economia Comportamental com a contribuição de Keynes, o que foi feito por meio de várias perspectivas, principalmente em razão da condição de incerteza. Gerrard (1997) apontou que a visão de Keynes sobre racionalidade se aproxima da "limitada" de Simon (1979) ao admitir suas limitações, bem como da "ecológica" de Gingerenzer (2001) por ter destacado a influência contextual. Fontada e Gerrard (2004) sustentaram a decisão sob incerteza como ênfase comum das abordagens de Keynes e da Economia Comportamental. Pech e Milan (2009) discutiram, sob o ponto de vista do comportamento, o papel das convenções na conduta individual, o animal spirit dos empresários, a formação de expectativas e a propensão a consumir. Fazzari (2009), Davidson (2010) e Koutsobinas (2014) apontaram para o papel psicológico das convenções no processo de escolha. Davidson (2010) e Koutsobinas (2014) foram além, atribuindo originalidade a Keynes na discussão de alguns insights que vieram a ser precursores de temas discutidos na Economia Comportamental, principalmente na tomada de decisão sob incerteza.

Entretanto, mesmo havendo premissas próximas sobre o processo de tomada de decisão dos indivíduos entre Keynes e a Economia Comportamental, cabe destacar que existem importantes diferenças metodológicas entre essas abordagens. A Economia Comportamental, principalmente a partir dos trabalhos de Kahneman e Tversky, tem pautado seus resultados em dados obtidos em experimentos de laboratório. De acordo com Levitt e List (2007) a atratividade desse método experimental na economia deve-se a sua capacidade de gerar observações, ceteris paribus, quanto às motivações individuais dos agentes econômicos, difíceis de se obter através da aplicação de técnicas econométricas convencionais às bases de dados já estabelecidas.

Porém, Levitt e List (2007) ressaltaram uma crítica aos experimentos de laboratório na economia: há problemas de validade externa, porque seus resultados podem não ser generalizáveis, já que o comportamento individual pode ser sensível a uma variedade de fatores que sistematicamente mudam entre o laboratório e o mundo exterior. Entretanto, conforme destacaram Camerer e Loewenstein (2004), por mais que a Economia Comportamental em sua origem fosse muito baseada em evidências obtidas a partir de experimentos, com o passar dos anos passou-se a ir além dos experimentos e com o avanço da capacidade de processamento dos computadores, o trabalho com Big Data tornou-se a fronteira na área. A Economia Comportamental, então, abraçou toda a gama de métodos empregados por outras 
subdisciplinas da economia, tornando-se cada vez mais próxima da economia mainstream na questão metodológica ao longo do tempo. Isso ocorreu, principalmente pela preocupação da Economia Comportamental em analisar de forma descritiva o comportamento individual, compatível com o individualismo metodológico adotado no mainstream.

Já em Keynes a preocupação não foi apenas com o comportamento individual, como apontou Corraza (2009), já que a TG transitou de uma visão individualista para outra mais organicista do sistema econômico. Nisso, a unidade de análise deixou de ser apenas o indivíduo, o comportamento microeconômico, e passou a ser os agregados, a dimensão macroeconômica da economia. Para Gerrard (1997), isso ocorreu porque Keynes acreditava que a estrutura apropriada na teoria econômica deveria dicotomizar entre a microeconomia da alocação de uma quantidade fixa de recursos e a macroeconomia de seu emprego agregado.

Segundo Bresser-Pereira (2009), a principal contribuição metodológica de Keynes foi o uso do método histórico-dedutivo para a análise do sistema econômico. Tal método inicia com a observação da realidade econômica, assume que o conhecimento anteriormente acumulado é razoavelmente válido, segue na busca de novos fatos, novas regularidades e tendências que estejam emergindo historicamente, para então buscar desenvolver um modelo de sistema que seja próprio ou complementar aos existentes. Neste caso, o modelo é intrinsecamente provisório, na medida em que a realidade sob estudo está historicamente mudando. Isso afasta a metodologia Keynesiana daquela do mainstream, cujas regularidades determinísticas são estabelecidas para terem em seus modelos uma validade independentemente dos contextos de tempo e lugar.

Portanto, do ponto de vista metodológico as visões de Keynes e da Economia Comportamental possuem diferenças importantes, a primeira está pautada na abordagem individualista, aproximando-se do mainstream, enquanto a segunda admite o holismo metodológico. Porém, ambas se aproximam por meio dos aspectos teóricos que o artigo quer destacar, a consideração da incerteza e seus resultados psicológicos enquanto condicionantes do comportamento, individual na Economia Comportamental e agregado na teoria Keynesiana.

Se essa proximidade entre as abordagens de Keynes e da Economia Comportamental permitirem deixar de lado suas diferenças metodológicas, pode-se dar continuidade a iniciativa de aproximação entre as duas abordagens. Neste sentido, o presente artigo ilustra a compatibilidade entre as modernas teorias da escolha na Economia Comportamental e a decisão de investimento em Keynes. Esse esclarecimento contribui com a teoria econômica, ao fazer uma revisão na História 
do Pensamento Econômico, utilizando os trabalhos de Keynes e da Economia Comportamental para oferecer maior compreensão sobre ambas as abordagens e, possivelmente, para o campo de estudo mais geral da tomada de decisão. Serão destacados aqui dois pontos de convergência entre as duas abordagens: (i) a relação entre racionalidade e incerteza; e (ii) a proximidade entre heurísticas e convenções.

Gerrard (1997) verifica a relação entre racionalidade e incerteza na EC e nos trabalhos de Keynes. Partindo-se da TG, tem-se a consideração Keynesiana de que os indivíduos aprendem com base na experimentação, como afirmam Bresser-Pereira (2009), Corazza (2009) e Ferrari-Filho e Terra (2016). Porque, sabendo-se inseridos em um ambiente incerto, os agentes econômicos da abordagem Keynesiana trabalham com dois objetivos no processo decisório, a busca por ganhos e a precaução. Se isso é verdadeiro, a racionalidade aí implica algo diferente daquela na economia tradicional. Resulta, como em Katona (1953) e Gingerenzer (2001), na capacidade de adaptação às situações para o melhor proveito, sem guardar relação determinística entre as opções disponíveis e o resultado da decisão. Ou seja, os agentes podem ter suas escolhas condicionadas pelas expectativas.

Outro ponto de convergência ocorre entre os conceitos convenção e heurística, como sustentado por Fazzari (2009), Davidson (2010) e Koutsobinas (2014). Como visto, Keynes (e.g. 1936; 1937b) utilizou o termo convenções para designar um comportamento simplificador na tomada de decisão, que, em última instância, é a utilização de alguma informação presente para a criação de expectativas quanto ao futuro. A relevância desse aspecto na TG foi destacada por Fazzari (2009), que apontou que essas convenções surgem das relações sociais entre os agentes, e por Oreiro (2011), quando destacou o papel que as convenções têm em coordenar ações individuais ao reduzir a incerteza. Se há na proposta Keynesiana uma atividade que busca simplificar a escolha, isso é compatível com aquilo que as propostas sobre heurísticas possuem como elemento comum, a noção apontada por Shah e Oppenheimer (2008) de atalhos que reduzem esforços na decisão. Logo, as convenções Keynesianas podem ser lidas como as heurísticas utilizadas pelos agentes na inferência psicológica sobre as condições futuras da economia que, uma vez incertas, precisam ser especuladas para as escolhas presentes.

De maneira geral, é possível relacionar as teses gerais de Keynes e da Economia Comportamental antes de se passar à análise do tema central do artigo, a tomada de decisões. Isso porque ambas enfatizam a incerteza em suas análises. Como Dequech (1999a) apresenta, a incerteza fundamental é a situação em que não se pode saber com precisão sobre o futuro porque uma parte essencial da informação acerca dele está ausente e não pode ser inferida. 
Isso é válido na teoria Keynesiana tanto no comportamento geral da economia, que é inerentemente incerto, quanto nas decisões individuais, que são moldadas pelos aspectos psicológicos dos agentes econômicos, que as tornam flexíveis e adaptáveis. Como foi visto, uma forma como essa incerteza diminui se dá pelo uso do método das convenções, que promove maior convergência, e por isso alguma previsibilidade, das ações individuais e dos padrões do comportamento agregado na economia. ${ }^{13}$

Isso também vale na Economia Comportamental ao se observar o que se entende por racionalidade nesta abordagem. Se é considerada a racionalidade limitada discutida por Simon, esta tratou da capacidade cognitiva dos agentes, uma característica do indivíduo. Se observada a racionalidade ecológica de Gigerenzer, esta discutiu a adaptação cognitiva dos agentes ao ambiente, que deriva/depende de um estímulo provocado por uma característica do ambiente. Neste mote, pode-se afirmar que ambas as propostas sobre a racionalidade fazem menção à incerteza, com Simon discutindo a capacidade individual incerta frente ao processamento das informações, e Gigerenzer destacando que há incerteza sobre qual será a reação individual a um determinado ambiente. Logo, na Economia Comportamental também pode-se afirmar que a incerteza tem tanto um caráter individual (indivíduo) quanto geral (ambiente), ambos superados por meio do uso de heurísticas pelos agentes econômicos que formam padrões de comportamento individual e geral na economia.

\subsection{Relações teóricas entre a escolha na Economia Comportamental e a decisão de investimento em Keynes}

Se existe uma relação próxima entre o arcabouço da Economia Comportamental e a base teórica de Keynes, cabe investigar a aproximação dessas duas abordagens para a tomada de decisões. A proposta desta subseção é mostrar o ponto central do artigo: a possibilidade de ilustrar as modernas teorias de escolha na Economia Comportamental, a Teoria do Prospecto e a teoria da Contabilidade Mental, por meio da decisão de investimento explicada por Keynes na TG. Isso é importante na medida em que reforça as relações teóricas entre as duas abordagens, bem como permite uma compreensão maior acerca de cada uma delas.

A Teoria do Prospecto foi sugerida inicialmente por Kahneman e Tversky (1979) como forma de contrapor a teoria da utilidade esperada da economia

\footnotetext{
13 "Nevertheless, individuals are more ignorant at least about some things-such as possible future values of nominal variables-in some situations than in others, the difference between these situations depending on the existence and prevalence of stabilizing institutional practices. It is in this specific sense that the degree of fundamental uncertainty can be larger in some circumstances than in others." (Dequech, 1999a, p. 416-417)
} 
tradicional. Segundo a nova proposta, os julgamentos individuais seriam realizados com base em algum ponto de referência e diferentes sentimentos com relação a ganhos e perdas. ${ }^{14}$ Partindo disso, o processo imediatamente anterior à decisão foi considerado dividido em duas etapas: (i) edição, em que os agentes simplificam o processo de escolha; ${ }^{15}$ (ii) avaliação, em que os possíveis resultados são julgados com base em algum parâmetro.

Como visto, a decisão de investimento na Teoria Geral depende da eficiência marginal do capital. Em síntese, a expectativa de que a aquisição de capital permite retornos líquidos positivos ao longo do tempo com relação ao seu custo inicial e de manutenção. Então é possível estabelecer que os empresários simplificam os elementos necessários em sua decisão de Investir de duas formas: (1) admitindo a taxa de juros como uma simplificação para os custos, já que ela representam custo de oportunidade no uso dos recursos ou na obtenção de empréstimo; (2) sustentando que os rendimentos esperados, por serem reconhecidamente incertos, possam ser inferidos psicologicamente com base nas variáveis que conduzem suas expectativas: convenções, usando as informações sobre o presente, ou os níveis de produção e preço, ou ainda a opinião geral sobre o futuro; o animal spirit, a propensão a Investir que os empresários possuem; a confiança que tais agentes têm em suas próprias expectativas.

Com base nas duas abordagens, é possível atribuir à decisão de investimento em Keynes as duas fases propostas na teoria do Prospecto. Como as duas teorias admitem os efeitos de um ambiente incerto, a fase de edição das opções tem relevância acentuada, porque sujeita aos vieses de comportamentos. Embora a especulação sobre os custos seja simplificada atribuindo-os à taxa de juros, a formação de expectativas sobre os rendimentos é um processo de imaginação do próprio empresário. Algo que o próprio Keynes reconheceu ao tratar da confiança, bem como dos sentimentos presentes na sociedade que influenciavam a todos, como otimismo e pessimismo.

Se não é possível ir muito além nessas relações porque Keynes não se aprofundou nas questões psicológicas, é fácil encarar o efeito da segunda fase da teoria do Prospecto sobre a avaliação. Porque, reconhecendo que as opções disponíveis ao empresário são comparadas com um ponto de referência, na teoria Keynesiana este será necessariamente a taxa de juros. Na Teoria Geral cada uma das

${ }^{14}$ O que promove a substituição da "aversão ao risco" utilizada na teoria tradicional pela "aversão à perda" (Kahneman e Tversky, 1979; Kahneman, 2012).

${ }^{15}$ É a identificação desta fase que tem aproximado as pesquisas de Economia e Psicologia desde a década de 1970, pela verificação dos vieses de comportamento que distorcem a percepção dos agentes econômicos na simplificação das escolhas, como mostra Kahneman (2012). 
oportunidades de investimento é avaliada pelos empresários em relação ao limite inferior de rendimentos que se espera receber deles, qual seja, seu custo de oportunidade representado pela taxa de juros. Um balizador que, de maneira simplificada, dita a dicotomia entre gastos produtivos ou aplicações financeiras, ou ainda, entre ampliação da capacidade produtiva e os custos de realizá-la.

$\mathrm{Na}$ teoria Keynesiana, os investimentos cessam quando a eficiência marginal do capital se iguala à taxa de juros. Uma posição de equilíbrio que pode ser analisada à luz da teoria do Prospecto como o ponto em que os empresários percebem encerradas as possibilidades de ganhos relativos a partir da realização de novos investimentos. Desta forma, é possível afirmar que, em Keynes, os empresários fazem prospecções da renda futura embasados em expectativas formadas a partir de fatos particulares e senso comum na economia, mas ancorados na taxa de juros. ${ }^{16}$ Assim, a decisão de investimento em Keynes tem sua volatilidade dada pela mudança nas expectativas, nos juros ou ainda, como se quer destacar: na relação de ajuste que os empresários realizam subjetivamente entre resultados esperados e a âncora com a qual eles são comparados.

Baseado na teoria do Prospecto, Thaler (1985, 1999) propôs a tese da Contabilidade Mental, uma abordagem teórica de escolha na Economia Comportamental que reconsidera como o processo decisório dos indivíduos é organizado e gera impactos na decisão. Admitindo que os indivíduos levam em conta ganhos e perdas esperados para cada escolha, nesta versão a decisão também ficou dividida em duas etapas: (i) análise de ganhos e perdas potenciais de cada opção com base em algum ponto de referência; (ii) aprovação ou reprovação de cada alternativa de acordo com a perspectiva de resultado. Conquanto a proximidade com a teoria do Prospecto, se destacaram como novidades na teoria da Contabilidade Mental as ideias de utilidade da transação e a atitude deliberada de abertura ou fechamento de contas mentais.

Thaler (1985) afirmou que os indivíduos não auferem utilidade apenas no consumo de um bem, mas também na sua aquisição. A compra de um produto permite utilidade ao agente econômico por duas vias: (i) diretamente, pela realização da aquisição; (ii) indiretamente, pelo julgamento de valor feito pelo indivíduo da

\footnotetext{
${ }^{16}$ Pech e Milan (2009) destacam o papel do animal spiritnessa relação entre a decisão de investimento em Keynes e a EC. Para os autores, elementos discutidos na EC ajudam a explicar a propensão à Investir. Fatores como excesso de confiança (crença psicológica superestimada das próprias capacidades) ou de otimismo (otimismo não realista) enviesariam pela decisão de investir, enquanto viés de status-quo (propensão a não agir) e aversão à ambiguidade (preferência por resultados certos aos possíveis) levariam à rejeição do investimento.
} 
própria transação efetuada. Logo, o sentimento despertado no indivíduo pela realização da transação implica na alteração da utilidade total de uma aquisição. ${ }^{17}$

A segunda novidade inserida por Thaler (1999) tratou do processo de abertura e fechamento de contas mentais. $O$ estabelecimento dessas contas dependeria do particionamento da restrição orçamentária individual em diferentes segmentos, de acordo com as preferências de agregação dos indivíduos, em que ocorre um escalonamento de prioridade entre as contas, assim como entre os itens dentro delas. ${ }^{18}$ Esse processo seria útil ao reduzir os custos na tomada de decisão, ajudando em problemas como o autocontrole, pela definição de categorias de despesa e fonte de recursos para seu suprimento. Porém, tal processo fica sujeito aos vieses de comportamento, sendo o principal deles a discricionariedade dos indivíduos em abrir ou fechar uma conta mental.

Considerando a abordagem da Contabilidade Mental sob esses dois aspectos, a utilidade da transação (Thaler, 1985) e a administração de contas mentais (Thaler, 1999), é possível associá-la à decisão de investimento em Keynes. Como mostrado, na TG os empresários decidem com base na vontade própria, originada em sua percepção de mundo por meio de características particulares e fatos sociais. 0 principal balizador de suas decisões é a taxa de juros, utilizada como ponto de referência por se configurar naturalmente como alternativa ao uso dos recursos ou custos do empreendimento.

Se as ideias Keynesianas são aplicadas à tese da Contabilidade Mental, é possível discutir em que medida os empresários obtêm utilidade na realização de investimentos pelo próprio ato de transacionar, uma explicação plausível para sua propensão a Investir, o animal spirit. Uma vez que o próprio Keynes não definiu a natureza dessa característica, é possível encontrar na Economia Comportamental uma fonte de explicação, a utilidade de transação proposta por Thaler (1985). Neste sentido, o animal spirit também serve de guia para explicar no mundo real porque alguns indivíduos são mais propensos que outros na realização de empreendimentos, permitindo considerar tal aptidão como elemento-chave para a disposição em abrir essa conta mental.

\footnotetext{
17 Um exemplo natural é a avaliação de justiça na transação, cujo julgamento sobre esse aspecto implicará maior ou menor utilidade na compra.

${ }^{18}$ Para Heath e Soll (1996), há duas etapas principais no processo de escolha baseado na contabilidade mental: (1) a fixação de uma conta específica; e (2) o rastreamento das despesas em andamento nesta conta em relação ao orçamento que inicialmente lhe foi imputado. A primeira etapa seria decorrente do planejamento, como forma de conter ações impulsivas, enquanto a segunda consiste no controle das contas, respeitando-se seu orçamento.
} 
Outra questão relevante é a taxa de juros em Keynes como ponto de referência para a dinâmica das contas mentais em Thaler (1999). Se a eficiência marginal do capital tem como piso a taxa de juros, é possível afirmar que ela serve de parâmetro para especular acerca de decisões de investimento previamente contingenciadas pelos indivíduos. De acordo com Keynes (1936 [1985], capítulo 11), na relação entre eficiência marginal do capital e juros, respectivamente: (i) se maior, decide-se pelo investimento; (ii) se menor, mantém-se as coisas como estão; (iii) se igual, há um equilíbrio que não influencia pelo aumento da capacidade produtiva. Assim, como determinados empreendimentos só são viáveis a partir de determinado nível de custos, diretos ou de oportunidade, a taxa de juros pode ser apontada como gatilho que trava ou destrava determinadas contas mentais na consideração do empresário. quadro 1 sintetiza os elementos teóricos discutidos nessa subseção e a relação proposta entre eles.

\section{Quadro 1. Síntese das relações teóricas entre a escolha na Economia Comportamental e a decisão de investimento em Keynes}

\begin{tabular}{|c|c|c|}
\hline $\begin{array}{l}\text { Decisão de investir } \\
\text { em Keynes }\end{array}$ & $\begin{array}{c}\text { Teoria do } \\
\text { prospecto/contabilidade } \\
\text { mental }\end{array}$ & $\begin{array}{l}\text { Relação entre os aspectos para a decisão do } \\
\text { empresário }\end{array}$ \\
\hline $\begin{array}{l}\text { Expectativa de retorno } \\
\text { e taxa de juros }\end{array}$ & $\begin{array}{l}\text { Fase de edição e } \\
\text { avaliaçãa); avaliaçãa de } \\
\text { ganhos e perdas em } \\
\text { relação a um ponto de } \\
\text { referência }\end{array}$ & $\begin{array}{l}\text { Na fase de edição os empresários escolhem a } \\
\text { taxa de juros como simplificação dos custos de } \\
\text { aquisição do capital e formam suas expectativas } \\
\text { de retornos futuros; Na fase de avaliação os } \\
\text { empresários comparam os retornos esperados } \\
\text { com a taxa juros enquanto ponto de referência. }\end{array}$ \\
\hline Animal spirit & Utilidade de transação & $\begin{array}{l}\text { Animal spirit representa uma manifestação da } \\
\text { utilidade de transação que os empresários } \\
\text { auferem pelo simples ato de realizarem novos } \\
\text { empreendimentos. }\end{array}$ \\
\hline Incerteza fundamental & $\begin{array}{l}\text { Função ponderação de } \\
\text { decisão }{ }^{19}\end{array}$ & $\begin{array}{l}\text { A teoria do prospecto trata a incerteza como } \\
\text { uma percepção subjetiva do risco, com } \\
\text { probabilidades conhecidas, porém, no contexto } \\
\text { da incerteza fundamental, essa percepção dos } \\
\text { empresários se dá apenas pela confiança nas } \\
\text { próprias expectativas, pois as probabilidades } \\
\text { não são conhecidas. }\end{array}$ \\
\hline $\begin{array}{l}\text { Relação entre } \\
\text { eficiência marginal do } \\
\text { capital e taxa de juros }\end{array}$ & $\begin{array}{l}\text { Abertura e fechamento } \\
\text { das contas mentais }\end{array}$ & $\begin{array}{c}\text { Se os empresários percebem uma relação } \\
\text { favorável entre eficiência marginal do capital e } \\
\text { taxa de juros eles abrem contas mentais } \\
\text { direcionadas ao investimento, e assim o fazem } \\
\text { enquanto a relação for favorável, mantendo a } \\
\text { conta aberta. Ouando essa relação é ou torna-se } \\
\text { desfavorável ou equilibrada a conta mental é } \\
\text { fechada e os empresários param de direcionar } \\
\text { recursos ao investimento. }\end{array}$ \\
\hline
\end{tabular}

Fonte: Elaboração própria a partir das intormações levantadas na pesquisa.

19 *Kahneman e Tversky (1979) tratam a ponderação da decisão como uma função das probabilidades reais, porém não iguais as mesmas. Tversky e Kahneman (1992) estabelecem formas funcionais para função de ponderação sobre ganhos $\mathrm{w}^{+}(\mathrm{p})$ e função de ponderação sobre perdas $\mathrm{w}(\mathrm{p})$. 
Logo, é possível analisar que a decisão de investimento em Keynes à luz da Contabilidade Mental de Thaler implica que os empresários abrem uma conta de empreendimento quando há uma relação favorável entre eficiência marginal do capital e taxa de juros. Essa conta fecha quando tal relação é desfavorável ou está equilibrada. Portanto, há na teoria da Contabilidade Mental uma alternativa para explicar a tendência ao equilíbrio entre eficiência marginal do capital e taxa de juros na dinâmica econômica: o processo de abertura e fechamento de contas mentais pelos empresários.

\section{Considerações finais}

Este artigo buscou aproximar as contribuições teóricas a respeito das decisões dos agentes econômicos da moderna Economia Comportamental, principalmente a partir da década de 1970, daquelas promovidas por Keynes ainda na década de 1930. Para isso, foram enfatizadas as possibilidades de ler em via dupla as contribuições teóricas de uma proposição à luz da outra, de onde emerge uma complementariedade entre elas. Em especial, isso foi realizado para o conceito de racionalidade limitada e para as modernas teorias de escolha na Economia Comportamental, a Teoria do Prospecto e a Teoria da Contabilidade Mental, em uma possível relação com a de decisão de investimento em Keynes.

O artigo conclui pela possibilidade de uma complementariedade nas leituras da Economia Comportamental e da contribuição de Keynes. Foi mostrado, entre outras coisas, como na decisão de investimento, os juros podem ser lidos como um atributo heurístico usado em substituição a custo. Discutiu-se como o animal spirit é um atributo individual cuja natureza pode ser atribuída a um viés de comportamento, a atribuição de utilidade pela própria decisão de investir. Da mesma forma, essa propensão pode ser lida como explicativa para a abertura de contas mentais empreendedoras, enquanto a relação do indivíduo com relação aos juros serve de alerta latente para a abertura de contas mentais até então contingenciadas. Mostrou-se como essa dinâmica que faz a economia caminhar para o equilíbrio entre eficiência marginal do capital e taxa de juros em Keynes pode ser explicada pela dinâmica entre abertura e fechamento de contas mentais pelos empresários na economia.

Por fim, cabe ressaltar que o presente artigo não esgota a tentativa de relacionar Economia Comportamental e a teoria de Keynes. Em especial, aqui estão enfatizados os elementos de aproximação entre essas abordagens para mostrar as relações teóricas entre suas propostas para a tomada de decisão. $\bigcirc$ relacionamento entre as modernas teorias da escolha na Economia Comportamental, teoria do Prospecto de Kahneman e Tversky (1979) e Contabilidade Mental de Thaler (1985, 
1999), e a descrição da atividade dos empresários na TG de Keynes (1936), é promissora por três motivos: (1) é possível um melhor entendimento da teoria Keynesiana com base nos aspectos psicológicos da Economia Comportamental que não foram objeto da investigação de Keynes em sua proposição; (2) a decisão de investimento na TG servir de ilustração de como funciona o processo de escolha na teoria do Prospecto ou na Contabilidade Mental, aumentando a compreensão dessas propostas; (3) a sinergia entre essas diferentes abordagens é capaz de aumentar a capacidade teórica no campo da investigação sobre a tomada de decisões.

\section{Referências}

Berg, N. (2014) "The consistency and ecological rationality approaches to normative bounded rationality". Journal of Economic Methodology 21(4), p. 375-395. doi: 10.1080/1350178X.2014.969910

Bresser-Pereira, L. C. (2009) "Os dois métodos e o núcleo duro da teoria econômica", Revista de Economia Política 29(2), p. 163-190. doi: 10.1590/S010131572009000200001

Camerer, C. F. e Loewenstein, G. (2004) "Behavioral economics: past, present, future". In: Camerer, C. F., Loewenstein, G. e Rabin, M (org). Advances in Behavioral Economics. Princeton University Press, p. 3-51. doi: 10.1515/9781400829118-004

Corazza, G. (2009) "Aspectos metodológicos do pensamento de Keynes", 370 Encontro Nacional de Economia ANPEC, Foz do Iguaçu, Disponível em http://www.anpec.org.br/encontro2009/inscricao.on/ ac2098c6197baaef.doc, Acessado em 6 de outubro de 2019.

Davidson, P. (1999) "Colocando as evidências em ordem: Macroeconomia de Keynes versus velho e novo keynesianismo", In: Lima, G. T.; Sicsú, J.; Paula, L. F. (org.). Macroeconomia moderna: Keynes e a economia contemporânea, Rio de Janeiro: Campus, p. 35-64.

Davidson, P. (2002) "Financial markets, money and the real world". Edward Elgar.

Davidson, P. (2003) "Resgatando a revolução keynesiana", In: Lima, G. T.; Sicsú, J. (org.). Macroeconomia do emprego e da renda: Keynes e o keynesianismo, São Paulo: Manole, p. 3-28.

Davidson P. (2010) "Behavioral Economists should make a turn and learn from Keynes and Post Keynesian economists", Journal of Post Keynesian Economics 33(2), p. 251-254. doi: 10.2307/23035714

Dawes, R. M. e Thaler, R. H. (1988) "Anomalies: Cooperation", Journal of Economic Perspectives 2 (3): 187-197. doi: 10.1257/jep.2.3.187

Dekker, E. e Remic, B. (2019) "Two types of ecological rationality: or how to best combine psychology and economics". Journal of Economic Methodology 26(4), p. 291-306. doi: 10.1080/1350178X.2018.1560486 
Dequech, D. (1999a) "Expectations and confidence under uncertainty". Journal of Post Keynesian Economics 21(3), p. 415-430. doi: 10.1080/01603477.1999.11490205

Dequech, D. (1999b) "Incerteza num sentido forte: significado e fontes", In: Lima, G. T.; Sicsú, J.; Paula, L. F. (org.). Macroeconomia moderna: Keynes e a economia contemporânea, Rio de Janeiro: Campus, p. 88-108.

Diamond, P. e Vartianem, H. (2007) Behavioral Economics and its applications. Princeton University Press.

Fazzari, S. (2009) "Keynesian macroeconomics as the rejection of classical axioms", Journal of Post-Keynesian Economics, 32(1), p. 3-18. doi: 10.2753/PKE01603477320101

Ferrari-Filho, F. e Terra, F. H.B. (2016) "Induction as Keynes' method", In: FerrariFilho, F.; Terra, F. H. B. (org.). Ensaios sobre os 80 anos da Teoria Geral, Porto Alegre: Tomo Editorial, p. 51-70.

Fontana, G. e Gerrard, B. (2004) "A Post Keynesian theory of decision making under uncertainty", Journal of Economic Psychology 25, p. 619-637. doi: 10.1016/j.joep.2003.11.001

Gerrard, B. (1997) "Method and methodology in Keynes's General Theory", In: Harcourt, C. C.; Riach, P. A. (org). A second edition of General Theory (vol. 2), Routledge, p. 166-202.

Gigerenzer, G. (2001) "The adaptive toolbox", In: Gigerenzer, G.; Selten, R. (org). Bounded rationality: The adaptive toolbox, MIT press, p. 37-50.

Gigerenzer, G. (2008) "Why heuristics work". Perspectives on psychological science 3(1), p. 20-29. doi: 10.1111/j.1745-6916.2008.00058.x

Gigerenzer, G. (2019) "Axiomatic rationality and ecological rationality". Synthese, p. 1-18. doi: 10.1007/s11229-019-02296-5

Gigerenzer, G. e Brighton, H. (2009) "Homo heuristicus: Why biased minds make better inferences". Topics in cognitive science, 1(1), p. 107-143. doi: 10.1111/j.1756-8765.2008.01006.x

Gigerenzer, G. e Gaissmaier, W. (2011) "Heuristic decision making." Annual Review of Psychology, 62, p. 451-482, 2011. doi: 10.1146/annurev-psych-120709. 145346

Gigerenzer, G. e Todd, P. M. (1999) Simple heuristics that make us smart, Oxford University Press.

Heath, C. e Soll, J. B. (1996) "Mental budgeting and consumer decisions", Journal of Consumer Research, 23(1), p. 40-52. doi: 10.1086/209465

Howitt, P. (1997) "Expectations and uncertainty in contemporary Keynesian models", In: Harcourt, C.C.; Riach, P.A. (org.). A second edition of General Theory (vol. 2), Routledge, p. 238-260.

Just, D. R. (2013) Introduction to Behavioral Economics. Wiley Global Education.

Kahneman, D. (2012) "Rápido e devagar: duas formas de pensar", Rio de Janeiro: Objetiva. 
Kahneman, D. e Frederick, S. (2002) "Representativeness revisited: Attribute substitution in intuitive judgment". In: Gilovich, T.; Griffin, D.; Kahneman, D. (ed.), Heuristics and biases. New York: Cambridge University Press, p. 49-81. doi: 10.1017/CBO9780511808098.004

Kahneman, D. e Tversky, A. (1979) "Prospect theory: an analysis of decision under risk", Econometrica 4(2), p. 263-291. doi: 00129682(197903) 47:2<263:PTAAOD>2.0.CO;2-3

Kahneman, D., Knetsch, J. L. e Thaler, R. H. (1991) "Anomalies: The endowment effect, loss aversion, and status quo bias", Journal of Economic Perspectives, 5 (1), p. 193-206. doi: 10.1257/jep.5.1.193

Katona, G. (1953) "Rational behavior and economic behavior", Psychological Review 60(5), p. 307-318. doi: 10.1037/h0060640

Keynes, J. M. (1936 [1985]) “A teoria geral do emprego, do juro e da moeda”, São Paulo: Abril Cultural.

Keynes, J. M. (1937a [1984]) "A teoria da taxa de juros", In: Szmrecsányi, T. (org.). John Maynard Keynes, Editora Ática, p. 160-166.

Keynes, J. M. (1937b [1984]) "A teoria geral do emprego", In: Szmrecsányi, T. (org.). John Maynard Keynes, Editora Ática, p. 167-179.

Keynes, J. M. (1937c [2010]) "A teoria ex ante da taxa de juros", In: Clássicos da literatura econômica: textos selecionados de macroeconomia, $3^{\text {a }}$ edição, Brasília: IPEA, p. 335-341.

Koutsobinas, T. T. (2014) "Keynes as the first behavioral economist: the case of the attribute-substitution heuristic", Journal of Post Keynesian Economics 37(2), p. 337-355. doi: 10.2753/PKE0160-3477370207

Levitt, S. D. e List, J. A. (2007) "What do laboratory experiments measuring social preferences reveal about the real world?" The journal of economic perspectives 21(2), p. 153-174. doi: 10.1257/jep.21.2.153

Loewenstein, G. e Thaler, R. H. (1989) "Anomalies: Intertemporal choice". Journal of Economic Perspectives 3(4), 1989, p. 181-193. doi: 10.1257/jep.3.4.181

Miranda, J. C. R. (1997) "A economia monetária”, In: Carneiro, R. (org.). Os Clássicos da Economia, volume2, São Paulo: Editora Ática, p. 97-106.

Mousavi, S. e Gigerenzer, G. (2014) "Risk, uncertainty, and heuristics". Journal of Business Research 67(8), p. 1671-1678. doi: 10.1016/j.jbusres.2014.02.013

Oreiro, J. L. (2011) "Economia pós-keynesiana: origem, programa de pesquisa, questões resolvidas e desenvolvimentos futuros", Ensaios FEE, 32(2), p. 283312.

Pech, W. e Milan, M. (2009) "Behavioral economics and the economics of Keynes", The Journal of Socio-Economics 38(6), p. 891-902. doi: 10.1016/j.socec.2009.06.011

Shah, A. K. e Oppenheimer, D. M. (2008) "Heuristics made easy: an effort-reduction framework", Psychological bulletin, 134(2), p. 207-222. doi: 10.1037/00332909.134.2.207 
Silva, G. R. S. S. e Curado, M, L. (2016) "Precificação de ativos e mercados financeiros: um comparativo entre a teoria convencional das finanças, teoria Pós-Keynesiana e Behavioral Finance", Análise Econômica 34(65), p. 131-158. doi: 10.22456/2176-5456.49994

Simon, H. A. (1959) "Theories of decision-making in economics and behavioral science", American Economic Review, 49(3), p. 253-283.

Simon, H. A. (1979) "Rational decision making in business organization", American Economic Review 69(4), p. 493-513.

Szmrecsányi, T. (1984) (org.). "John Maynard Keynes", Editora Ática.

Thaler, R. H. (1985) "Mental accounting and consumer choice", Marketing science 4(3), p. 199-214. doi: 10.1287/mksc.4.3.199

Thaler, R. H. (1987) "Anomalies: the January effect", The Journal of Economic Perspectives 1(1), p. 197-201. doi: 10.1257/jep.1.1.197

Thaler, R. H. (1988) "Anomalies: The winner's curse", The Journal of Economic Perspectives 2(1), p. 191-202. doi: 10.1257/jep.2.1.191

Thaler, R. H. (1999) "Mental accounting matters", Journal of Behavioral Decision making 12(3), p. 183-206. doi: 10.1002/(SICI)10990771(199909)12:3<183::AID-BDM318>3.0.CO;2-F

Todd, P. M. e Gigerenzer, G. (2007) "Environments that make us smart: Ecological rationality". Current Directions in Psychological Science 16(3), p. 167-171. doi: 10.1111/j.1467-8721.2007.00497.x

Todd, P., M. e Gigerenzer, G. (2012) "What is ecological rationality?", In: Odd, P., M.; Gigerenzer, G. (org.). Ecological rationality: Intelligence in the world. Oxford University Press, p. 3-30. doi: 10.1093/acprof:oso/9780195315448.003.0011

Tversky, A. e Kahneman, D. (1974) "Judgment under uncertainty: heuristics and biases”, Science 185(4157), p. 1124-1131. doi: 10.1126/science.185.4157.1124

Tversky, A. e Kahneman, D. (1992) "Advances in prospect theory: Cumulative representation of uncertainty". I Risk Uncertainty 5, p. 297-323. doi: 10.1007/BF00122574

Vieira, J. G. S. (2007) "A estrutura das revoluções científicas e a retórica na economia Keynesiana: quatro ensaios sobre o método na economia". Curitiba, 2007. 155 p. Tese - Departamento de Economia, Setor de Ciências Sociais Aplicadas, Universidade Federal do Paraná. 